\title{
«EL ERROR DE LOS ATEYSTAS». POSESIÓN DIABÓLICA, DISCERNIMIENTO E INCREDULIDAD EN EL PATROCINIO DE ÁNGELES Y COMBATE DE DEMONIOS (1652) DE FRANCISCO BLASCO LANUZA*
}

\author{
POR \\ ISMAEL DEL OLMO 1 \\ Universidad de Buenos Aires
}

\section{RESUMEN}

A través del análisis del Patrocinio de ángeles y combate de demonios (1652), estudiaremos cómo el clérigo español Francisco Blasco Lanuza intentó defender la realidad de la posesión diabólica frente a interpretaciones de corte naturalista. Se afirma que su estrategia es una respuesta al desafío de la incredulidad en la existencia de sustancias espirituales y que los endemoniados son presentados como evidencia física de verdades metafísicas centrales del cristianismo.

PALABRAS CLAVE: posesión diabólica; discernimiento; incredulidad; Francisco Blasco Lanuza.

\section{"EL ERROR DE LOS ATEYSTAS". DEMONIC POSSESSION, DISCERNMENT AND INCREDULITY IN THE PATROCINIO DE ÁNGELES Y COMBATE DE DEMONIOS (1652) OF FRANCISCO BLASCO LANUZA}

\begin{abstract}
Through an examination of the work Patrocinio de ángeles y combate de demonios (1652), we will analyze how the Spanish cleric Francisco Blasco Lanuza tried to defend the reality of possession against naturalistic interpretations of the phenomenon. This defense was a response to a growing disbelief concerning the existence of spiritual substances; thus, the demoniac appears as physical evidence of the metaphysical truths of Christianity.
\end{abstract}

KEY WORDS: Demonic possession; Discernment; Incredulity; Francisco Blasco Lanuza.

CÓMO CITAR ESTE ARTícUlo / CITATION: Del Olmo, I. 2018. «“El error de los ateystas'. Posesión diabólica, discernimiento e incredulidad en el Patrocinio de ángeles y combate de demonios (1652) de Francisco Blasco Lanuza». Hispania Sacra 70, 142: $495-507$. https://doi.org/10.3989/hs.2018.034

Recibido/Received 20-05-2016

Aceptado/Accepted 23-09-2016

\section{DEMONOLOGÍA, DISCERNIMIENTO, INCREDULIDAD}

Hacia 1640, una cronista española señalaba así una impactante epidemia de endemoniadas desatada en el Alto Aragón: «Y al tiempo que esto se escriue, no ay cosa mas sabida y publica, que auer en dos lugares de la montaña mas de dozientas y cincuenta mugeres (y cada dia se van

Este texto fue presentado en la Facultad de Filosofía y Letras de la Universidad de Zaragoza el 21 de diciembre de 2016, en el marco del Seminario de Historia Cultural. Agradezco a Eliseo Serrano Martín por su gentil invitación y al público presente, en especial a Ángel Gari Lacruz y Manuel Gómez de Valenzuela, por sus preguntas y comentarios.

1 delolmoismael@hotmail.com / ORCID iD: http://orcid.org/00000003-2935-8068 descubriendo otras) obsesas y espiritadas por maleficio de vn solo hombre». Agregaba que el Santo Oficio de la Inquisición de Zaragoza había castigado al culpable. ${ }^{2}$ En junio del mismo año, los Avisos Históricos de José Pellicer precisaban: «En Zaragoza ha celebrado Auto de Fe la Santa Inquisición. Entre varios numerosos delincuentes salió a él un caballero muy conocido llamado Pedro de Arruebo, señor de la Artosa». ¿La razón? «Endemonió a más de mil y seiscientas personas. Diéronle doscientos azotes y quedó condenado a galeras». ${ }^{3}$

\footnotetext{
2 Padilla Manrique y Acuña Aranda 1640: 539-540.

3 Utilizamos una edición tardía: Pellizer y Tobar 1790: 173.
} 
La noticia refiere a un caso de posesión diabólica colectiva que se vivió al norte del Imperio de Felipe IV entre 1637 y 1642, en el Valle de Tena, en las aldeas de Tramacastilla y Sandiniés, Villanúa, Saqués, Sallent, Jaca, Pueyo de Jaca y Piedrafita. Los exorcistas locales y los agentes de la Inquisición coincidieron en el origen de este mal: el pacto que un labrador rico de aquellas tierras, Pedro de Arruebo, sostenía con el demonio. Ese pacto le permitía ordenar a los espíritus malignos tomar posesión de los cuerpos de las mujeres del lugar. ${ }^{4}$

La historiografía reciente ha tomado nota del extraño suceso. El caso recibió atención en obras de estudiosos como Ángel Gari Lacruz y Gonzalo Gil González, quienes estudiaron los hechos a la luz de la psicología histórica5; fue tratado por Arturo Morgado García, Fabián Campagne y Andrew Keitt, quienes lo utilizaron en sus análisis sobre las creencias demonológicas, el discurso anti-supersticioso y la sacralidad regia en la España temprano-moderna, respectivamente ${ }^{6}$; Hillary Kallendorf ofreció una posible relación intertextual entre una obra de Cervantes Saavedra, El rufián dichoso, y uno de los relatos surgidos de esta epidemia diabólica. ${ }^{7}$ También ha estudiado el caso la especialista española María Tausiet, dedicándole un artículo completo publicado en inglés y castellano en 2006 y 2009, donde trata la epidemia a partir de las tres versiones escritas que suscitó y bajo la luz de las diversas teodiceas accesibles al pensamiento de la temprana modernidad. ${ }^{8}$

El presente artículo elige centrarse en otra arista del caso de Tena: el modo en que la posesión fue utilizada como evidencia de la realidad de las sustancias espirituales en una era en la que las verdades metafísicas esenciales del cristianismo estaban siendo fuertemente cuestionadas. Esta conexión entre demonio y descreencia se dará a partir del lenguaje de la experiencia sensorial de lo espiritual. ${ }^{9}$ La obra de Francisco Blasco Lanuza Patrocinio de ángeles y combate de demonios (1652), cuyas líneas seguiremos en nuestro artículo, participa de este lenguaje. Su autor, párroco y exorcista al momento de estallar la epidemia diabólica, advierte que el caso es impactante por «los terrores y efectos del demonio que se ha experimentado» de los que él mismo fue «testigo de vista». ${ }^{10}$ Escribe su obra, afirma, para dar noticia «de algunos secretos de la Diuina prouidencia» ${ }^{11}$; cuando en 1640 insistió en la necesidad de que la Inquisición interviniera en el Valle, clamó que estaba en juego «la suprema protección de la Fe». ${ }^{12}$ En lo que sigue, intentaremos develar el núcleo de estas sentencias.

4 Los documentos se reproducen en el apéndice que aporta Gari Lacruz 1991: 411-432 (reedición del texto en el año 2007). Los demonios mismos se revelan aliados de Arruebo: «Vellacos - había gritado una posesa durante el ritual- ¿qué buscáis? Ya se que benis contra nuestro Pedro de Arruebo» (Carta de Raimundo Saenz, citado en ibídem: 180).

5 Gari Lacruz 1991; Gil González 2011.

6 Campagne 2002: 175 y ss. y 276-277; Keitt 2005: 194 y ss.; Morgado García 1999: 46-47.

7 Kallendorf 2004: 1449-1466.

8 Tausiet 2006a: 233-255 y 2009: 125-146. Las tres versiones del suceso que se estudian son: Luis de la Concepción 1673; las cartas e informes que el inquisidor Bartolomé Guijarro y Carrillo redacta en 1640 (reproducidos en Gari Lacruz 1991: 411-432); y, sobre todo, Blasco Lanuza 1652.

9 Sobre este lenguaje, consúltese Houdard 2008: 212 y ss.

10 Citado en Gari Lacruz 1991: 163. Sobre el Patrocinio, ver Morgado García 2000: 107-130.

11 Blasco Lanuza 1652: 835.

12 Citado en Gari Lacruz 1991: 419.
El hilo que atraviesa la exposición de Blasco Lanuza es su obsesión por discernir entre etiologías naturales y preternaturales -aquí, diabólicas - de los síntomas desplegados por las mujeres afectadas. ${ }^{13}$ La demonología como ciencia teórica y práctica funcionó en esta oportunidad (como en muchas otras a lo largo de la temprana modernidad) como un campo de aplicación de los presupuestos teológicos del discernimiento de espíritus, es decir, el arte de discriminar qué orden de causalidad -el divino, el preternatural, el natural - animaba las afecciones y comportamientos percibidos en los sujetos. ${ }^{14} \mathrm{El}$ caso de la epidemia diabólica del Valle de Tena se inscribe así en uno de los conflictos medulares de la temprana modernidad, aquél de la búsqueda de certeza y de una distinción definitiva entre los planos de lo sobrenatural y lo natural -o más precisamente, de las diversas modalidades de su interconexión legítima. El intento por elucidar y dar sentido a hechos percibidos como extraordinarios constituye una parte fundamental de esta empresa. ${ }^{15}$

En los dos próximos apartados, buscaremos mostrar cómo y por qué Francisco Blasco Lanuza debió, por un lado, esclarecer la sospechosa similitud entre los síntomas corporales de la posesión demoníaca y aquellos despertados por la melancholia y el influjo astral y, por otro lado, dar cuenta de la relativa facilidad con la cual podía fingirse un estado posesorio. ${ }^{16}$ Sorprende en este sentido la insistencia con la que intentó salvar a las posesas de ser acusadas de pecadoras, enfermas o meras falsarias y, a la par, la obstinación con la que encadenó el traumático episodio al imperio de los demonios. Creemos, como diremos en el tercer apartado, que Blasco Lanuza debía probar a sus lectores el carácter eminentemente preternatural de las posesiones porque solo ese exclusivismo le permitiría construir una evidencia material en contra de la incredulidad (o, como él mismo lo llama, el ateísmo). Este conflicto argumentativo ofrece, por lo tanto, un cruce fértil entre las problemáticas asociadas del discernimiento, la descreencia y la demonología hacia mediados del siglo XVII.

\section{EN DEFENSA DE LAS POSESAS: INOCENCIA, NATURA Y DEMONIOS}

Cuando Bartolomé Guijarro y Carrillo, el inquisidor apuntado para investigar la epidemia diabólica en Tena, procede a explicar la causa del suceso, enfatiza que se debe a la «ydolatria y poca firmeza en la Fee» de las aldeanas del lugar. ${ }^{17}$ Sobre la necesaria permisión divina para la acción diabólica, razona Guijarro que la teología admite que sea el pecado propio y ajeno (o ninguno) lo que dispare el permiso

13 Sobre la categoría de lo preternatural, consúltese Daston 1991: 93-124; Daston 2000: 15-41. Para una discusión sobre la utilización actual que la historiografía hace de esta categoría, véase OssaRichardson 2013: 87-88.

14 Véase, entre los títulos más recientes, Campagne 2016; Copeland y Machielsen 2013. Para la conexión entre demonología y discernimiento en la primera modernidad, véase Caciola 2003; Caciola y Sluhovsky 2012: 1-48.

15 Sobre la relación entre crisis de certeza y discernimiento, véase Keitt 2005; Schreiner 2011.

16 De la abundante bibliografía dedicada a la melancolía en la Europa de la primera modernidad, señalemos la obra clásica de Klibansky et al. 1964, y la más reciente de Radden 2000. Para este tema en España, véase Atienza 2009; Gambin 2008.

17 Citado en Gari Lacruz 1991: 228. 
necesario para la posesión; en su opinión, sin embargo, «lo hordinario es permitir Dios que el demonio entre en los cuerpos humanos por pecados propios de los hombres». ${ }^{18}$ Como asiente la teodicea pacientemente construida desde Agustín de Hipona, el mal perceptible en el mundo es siempre parte de un bien mayor ${ }^{19}$; si Dios permite actuar al demonio, es para que las víctimas se ejerciten en obras espirituales. Que tengan, dice Guijarro, ocasión de «frecuentar mas los santos Sacramentos»:

Y esta es, a mi ber, la causa porque permite Dios estos males en las montañas, y no en la tierra llana, porque conociendo Dios que la gente de aquella tierra necesita de semejantes remedios, como Padre y Médico Espiritual, les da enfermedades que se curan con ellas. ${ }^{20}$

De manera alguna las opiniones del inquisidor son extrañas al pensamiento eclesiástico de la temprana modernidad. Se sabe que los misioneros católicos españoles de fines del siglo XVI y del XVII se lamentaban del bajo nivel de instrucción de sus feligreses, ignorancia que en el marco del élan misionero de la Contrarreforma sintetizaban en la expresión «Indias interiores». En este sentido, la región donde se desarrolla el caso de las posesas de Tena resulta paradigmática. ${ }^{21}$ Henry Kamen ha advertido ya hace tiempo que la religión sacramental que Trento se había ocupado por sistematizar significaba poco para el común del pueblo cristiano, en especial para los habitantes de las áreas más alejadas del centro español, donde apenas llegaba la estructura eclesiástica, como Cantabria, el País Vasco o los Pirineos; allí el clero secular era escaso y de baja formación (el clero regular, casi inexistente). ${ }^{22}$ Jaca, región principal de la epidemia que estamos estudiando, aparece explícitamente mencionada por el virrey de Aragón a fines del XVI, cuando suplica a los jesuitas que misionen en esas tierras pirenaicas, cuyos moradores se destacaban por su «grandissima ignorancia y poca doctrina». "Viven como fieras», agregaba. ${ }^{23}$ Para lo que nos compete aquí, notemos que la relación entre ignorancia e impiedad campesinas y demonología aparece como tópico en la literatura sobre posesión y exorcismo. En un afamado recetario para exorcistas, Benito Remigio Noydens asegura: "Suele tambien el demonio apoderarse de muchos por la notable ignorancia, y descuydo, que tienen de saber las cosas necessarias [...] para salvarse: y assi algunos dizen, que en las montañas de Asturias ay muchos endemoniados, assi hombres, como mugeres, que han vivido, y viven tan agrestes, como animales brutos». ${ }^{24}$ Como el inquisidor Bartolomé Guijarro, aún cuando Noydens admite la posibilidad de una intervención diabólica permitida directamente por la Divinidad «para mayor honra y gloria suya, y mas merecimiento del hombre», repite la razón usual: «de ordinario los pecados son causa deste gran trabajo». ${ }^{25}$

\footnotetext{
18 Ibídem: 429.

19 Para una excelente síntesis de la perspectiva agustiniana sobre el problema del mal, consúltese Evans 1994.

20 Gari Lacruz 1991: 429.

21 Sobre las «Indias interiores» en el contexto de la España del Antiguo Régimen, véase Contreras 2002: tomo V, 9-38. Consúltese también Prosperi 1996: 551-649.

22 Kamen 1998: 9.

23 Citado en Villagrán 2003: 62.

24 Noydens 1688: 101-102.

25 Ibídem: 8.
}

Muy por el contrario, dejar en clarola bondad y la piedad de las víctimas es el primer paso que emprende el Patrocinio de Francisco Blasco Lanuza en su defensa de las endemoniadas. La posesión diabólica no siempre supone culpa, "y menos indicio ay de ella quando sucede en muchos». ${ }^{26}$ Contrario al grueso de la opinión de la época, el autor comenta: «Sabed [...] que es la condición del demonio esta: no persigue sino a los buenos; muy desusado tiene el hacer armas contra los malos, porque son amigos suyos». ${ }^{27}$ No parecen hombres sabios, sino "vulgares» quienes reputan mal las zonas donde se extiende la posesión; no se dan cuenta, dice Blasco, que "muchas veces son inocentes y justos». ${ }^{28}$ Este alegato en favor de las posesas llega al punto de incluir entre ellas a pequeñas de corta edad, menos dadas al pecado por su raciocinio todavía débil: "Muchas veces reparé, viendo tanto número de espiritadas en el Valle de Tena, en que ninguna vi de las que tenían opinión de pecadoras o hechiceras, con ese achaque; solo mujeres de buena vida, doncellas sin indicios de graves culpas, niñas de 4, 5, 6, 7 años». ${ }^{29}$

Una vez propuesta la inocencia de las endemoniadas, Blasco prosigue su defensa en el ámbito de la etiología. Aquí conviene advertir brevemente que el grueso de los intelectuales cristianos de la temprana modernidad admite una interacción de órdenes de causalidad al momento de explicar las afecciones del cuerpo. Síntesis conflictiva de materialismo hipocrático-galénico y cultura judeo-cristiana, tenemos en la época una coexistencia de dos sistemas etiológicos, el naturalista o monocausal -que privilegia una interpretación impersonal de las afecciones- y el personalista o pluricausal -que admite la posibilidad de que agentes externos con intención causen violencias en el cuerpo. Como expone Stuart Clark, antes del Iluminismo la metafísica que rige lo real es otra y la naturaleza posee límites más amplios: estos límites incluyen la efectividad material, en el ámbito de la natura, de intervenciones espirituales, sean supernaturales, angélicas o humanas. ${ }^{30}$ Esto es lo que ocurre en el caso de la posesión diabólica, afección que conecta el orden natural con el orden preternatural demoníaco; en efecto, la natura cristiana, desde Agustín de Hipona y continuando durante la escolástica medieval, es una en la cual la existencia de acciones y efectos demoníacos está ampliamente presupuesta. ${ }^{31}$ Es así como, a menudo, el hecho de que el demonio operara en el ámbito de la naturaleza hizo que la posesión diabólica se solapara con otras enfermedades puramente naturales -en especial, y sobre todo a partir del Renacimiento, con la melancholia morbus. ${ }^{32}$ Hay multitud de intelectuales de la época que, interesados en la relación fluida entre demonios y natura, refieren esta interpenetración de los órdenes natural y preternatural para explicar la posesión diabólica como una afección que toma como base las

\footnotetext{
26 Blasco Lanuza 1652: 828.

27 Ibídem: 774.

28 Ibídem: 828.

29 Ibídem: 830.

30 Sobre estos sistemas de enfermedad, véase Levi 1990: 34-42. La referencia sobre la metafísica temprano-moderna como distinta de la ilustrada se encuentra en Clark 1997: 152.

31 Para un síntesis de los poderes del demonio en la natura según san Agustín y la escolástica tomista, véase Campagne 2011: 467-497. Sobre las ramificaciones temprano-modernas de esta relación entre demonio y naturaleza, véase Clark 1997: 149-312.

32 Véase más arriba, nota 16.
} 
disposiciones corporales de la víctima (entre ellos, Martín de Castañega y Johannes Wier por mencionar solo dos autores célebres en el ámbito de la demonología). ${ }^{33}$

Pero más allá de esta admitida confluencia entre explicaciones naturales y preternaturales en la cultura erudita temprano-moderna, a menudo asistimos al carácter agonal que presentaban las interpretaciones naturalistas o demonológicas del fenómeno posesorio. Este conflicto, que podemos vincular al desarrollo del naturalismo radical, ya estaba presente en el siglo XVI. También aquí pueden listarse nombres célebres. Piénsese si no, para el área italiana, en la lectura de la posesión diabólica hecha por el filósofo Pietro Pomponazzi, reduciéndola al influjo de los astros y la melancholia. ${ }^{34}$ En Francia, el Discours (1599) del médico de París Michel de Marescot, quien niega el carácter preternatural de la posesión de Marthe Brossier. ${ }^{35}$ En Inglaterra, las intervenciones de Reginald Scot, Edward Jorden y Samauel Harsnett en contra de posesos y exorcistas católicos y puritanos. ${ }^{36}$ En España, ya los Dialogos de philosophia natural y moral (1558) de Pedro de Mercado contienen huellas de la oposición entre humores y demonios al momento de explicar efectos materiales en el cuerpo. ${ }^{37}$ Hacia 1573, el Jardín de flores curiosas de Antonio de Torquemada rechazaba a los filósofos naturales y médicos que interpretaban la posesión diabólica en base a la melancholia. ${ }^{38}$ Como ejemplo concreto de este naturalismo radical, podemos referir a Juan Huarte de San Juan y su Examen de Ingenios (1575), donde también se recurre a la melancolía para elucidar síntomas a primera vista posesorios. ${ }^{39}$ El siglo de Francisco Blasco Lanuza

${ }^{33}$ Martín de Castañega opina así: «Es de notar que muchas veces la enfermedad corporal [...] es disposición para que el demonio tenga más entrada para atormentar aquel cuerpo, así mal dispuesto y enfermo» (Castañega 1997: 193). Johannes Wier, por su parte, es explícito respecto de la relación entre posesión y humores melancólicos: «ll faut avoir en tels cas un bon jugement, pour discerner ces diuerses maladies, qui souuentesfois sont acouplees ensemble». El demonio, dice, se mezcla intencionalmente con el humor melancólico, encontrándolo apto para ejecutar sus acciones. Wier se hace eco de una idea recurrente en su tiempo al referir a san Jerónimo, quien comenta que la melancolía es «le bain du diable» (citamos de la traducción al francés que Jacques Grévin realiza de la obra de Wier, De praestigis daemonum, originalmente publicada en 1563: Wier 1567: 441).

34 Lo hace tanto en el capítulo XIV de su De immortalitate animae, publicado en Bolonia en 1516, como en el capítulo X de su De incantationibus, escrito hacia 1525 pero publicado en Basilea en 1556. Sobre Pomponazzi, véase la obra clásica de Pine 1986; es útil también Biard y Gontier 2009.

35 Marescot 1599. Para esta controversia, véase la monografía de Pelletier 1998.

36 Jorden 1603; Scot 1584. Sobre los ataques de Harsnett y Jorden a posesos y exorcistas católicos y puritanos, véase Gibson 2006.

37 Mercado 1558: v, xvii [foliación personal a partir del «Diálogo Sexto»]. Sobre los Diálogos, véase Gambin 2008: 75-106.

38 Torquemada 1573 (citamos de una edición posterior, publicada en Amberes por Juan Corderio en 1575): "Y quando estos philosophos eran preguntados, que mal era el de los que estauan endemoniados, dezian que era vna passion que procedia de humor melancolico, y que la melancolia puede hazer aquellos effectos» (228). Y luego: «Aun agora los mas de los medicos quieren defenderlo, y de manera que confiessan y sustentan, quando el demonio habla diuersas lenguas, y en ellas cosas delicadas y subidas por la boca de vn rustico labrador, que todo procede del humor melancolico» (229).

39 Véase el capítulo IV de Huarte de San Juan 1575. Sobre este autor y su obra, consúltese el clásico de Read 1981, más la reciente obra de Duché-Gavet 2003. vería expandirse aún más esta lectura naturalista; baste mencionar aquí el escepticismo del filósofo italiano Giulio Vanini o de Thomas Hobbes. ${ }^{40}$ Por lo demás, dejemos en claro que la oposición entre posesión y enfermedad no pertenece a un desencantamiento secular del mundo: es atendida por las mismas autoridades eclesiásticas durante el seiscientos. Por ejemplo, la necesidad de distinguir entre demonios y melancolía aparece claramente tanto en las prescripciones vaticanas del Rituale Romanum (1614) respecto del exorcismo como en distintas constituciones sinodales españolas. ${ }^{41}$

Es importante notar aquí que el Patrocinio de Francisco Blasco Lanuza rechazará de plano este naturalismo radical y silenciará los entrecruzamientos entre los órdenes natural y preternatural al momento de explicar la epidemia del Valle de Tena, reclamando el estatus pleno de lo preternatural para los sufrimientos de las posesas. Lo interesante en este punto es la pretensión de exclusividad, ajena al grueso tanto de la filosofía natural como de la teología de la época. En efecto, Blasco Lanuza asienta su posición respecto de los síntomas de las endemoniadas: no poseen conexión alguna con causas naturales. Es sugestivo que se apoye en una sentencia de Tomás de Aquino profusamente utilizada en la primera modernidad por quienes insistían en clausurar las interpretaciones naturalistas de la posesión diabólica:

La misma razon lo dize, pues los atormentados de tales demonios, haze y dizen tales cosas, que ni a humanas fuerças, ni a virtud de estrellas, se puede atribuyr. Por consiguiente yerran los que atribuye tales efectos a humores melancolicos, o a virtud de astros. ${ }^{42}$

La mención de los astros y la melancolía, puntales del naturalismo radical arriba descripto, es muy significativa en este contexto; refuerza la impresión de que Blasco buscaba celosamente apartar a sus posesas de cualquier dispositivo natural que pudiera dilucidar su condición. Veamos otro

40 Vanini 1616 (especialmente el diálogo «De daemoniacis»); Hobbes 1651: 37-38. Sobre el escepticismo naturalista respecto de la posesión en el siglo XVII, consúltese Mandressi 2006.

41 Obsérvese la afirmación del Rituale: «In primis ne facile credat, aliquem à daemone obsessim esse, sed nota habeat ea signa, quibus obsessus dignoscitur ab ijs, qui vel atra bile, vel morbo aliquo laborant» (citamos de una edición tardía: Ritvale Romanvm Pavli V Pontifice Maximum Ivssv Editvm 1679: 192). Respecto de las constituciones sinodales, véanse, por ejemplo, las del obispado de Lugo en 1632: «Es tanta la rusticidad y vana creencia de muchos, que algunas enfermedades naturales, como es apoplexia y gota coral, dizen que son espiritus, o almas de los difuntos» (Constituciones Sinodales del Obispado de Lugo 1632: 117). En Málaga, en 1674, las instrucciones al exorcista son del mismo tenor, otorgando a los médicos un lugar de primer orden: el sacerdote debía consultarle si no era "excesso de melancolia» la causa verdadera detrás del aparente estado demoníaco (Constituciones Synodales del Obispado de Malaga 1674: 353).

42 Blasco Lanuza 1652: 810. La sentencia de Tomás de Aquino (que repetirá en su Summa, I, q. 115, a. 5) puede hallarse en su De malo (c. 1270): "Sed hoc apparet manifeste falsum, per hoc quod inueniuntur alique operationes demonum que nullo modo possunt ex aliqua naturali causa procedere, puta quod aliquis arreptus a demone loquitur linguam ignotam; et multa alia inueniuntur opera demonum tam in arrepticiis quam in nigromanticis artibus, que nullo modo possunt nisi ex aliquo intellectu procedere» (Citamos por la edición moderna de 1982. Tomás de Aquino 1982: 282). Esta sentencia es expresamente tomada por Heinrich Kramer en su Malleus Maleficarum (1486) - texto de referencia del Patrocinio, por otra parte- al momento de rechazar las lecturas naturalistas de la posesión diabólica (Kramer 2006: 312). 
ejemplo en la misma línea: Blasco alude, sin citarlas, a las palabras del Evangelio sobre las curas milagrosas de Jesucristo (Mateo, 4, 24: «Presentáronle todos los que estaban enfermos, y acosados de varios males y dolores, los endemoniados, los lunáticos, los paralíticos, y los curó»). La interpretación del pasaje es interesante:

No siempre son efectos de luna, y de humores melancólicos, como pretende dar a entender en las obsessas el demonio [...]. Aquellos hombres que tenían por lunaticos eran espiritados; y por engaño del demonio entendian que causaba aquellos efectos la luna, criatura de Dios. ${ }^{43}$

En contra de la letra misma de la Escritura (y de la corriente general de su época: "no siempre...») Blasco desliza que, en este contexto, lunático debe leerse como poseso. El demonio mismo había engañado a los antiguos judíos -y engaña ahora a los cristianos- haciéndoles creer que la luna o los humores (la natura) pueden afectar tan violentamente a los hombres. Notemos que Mateo 4, 24 en ningún momento menciona la melancolía. Blasco necesita añadirla al pasaje (para luego negarla) porque sus afinidades con la posesión diabólica eran demasiado estrechas para el siglo XVII, al punto de poder explicar por sí misma los exabruptos sintomáticos de las afectadas -de ahí, repitámoslo, que el mismo Rituale vaticano aconsejara discernir cuidadosamente entre endemoniados y melancólicos. Debía clausurarse cualquier etiología alternativa a la espiritual: ni los astros ni la bilis negra podían tener entonces nada que ver con las posesas.

Es importante insistir en este punto, pues consideramos que la relación entre naturaleza y preternaturaleza en el Patrocinio no ha sido tratada correctamente. Ángel Gari Lacruz, por ejemplo, centra su análisis en el pobre estado de la medicina de la época, insistiendo en que los síntomas eran vistos entonces como consecuencia de una invasión espiritual, cuando en realidad eran producto de disturbios mentales. Relatando los exorcismos emprendidos en las aldeas afectadas, Gari Lacruz comenta: «Tanto la actividad y aplicación de los medios como la escasa eficacia de los tratamientos queda reflejada así: 'un género de enfermedad tan secreta y extraordinaria que no podía darle alcance la diligente atención de los médicos'». ${ }^{44}$ Su cita proviene, justamente, del Patrocinio de Francisco Blasco Lanuza; con ella, Gari Lacruz busca mostrar que la poca efectividad de los remedios era incluso reconocida por los protagonistas de la época, quienes luego de fracasar con los medios naturales, se volcaban a prácticas espirituales. Esta línea ha sido enfatizada más recientemente por Gonzalo Gil González, quien comenta que en la España del XVII nada se sabía del inconsciente ni de los desórdenes de personalidad, imputándose así las afecciones mentales al ámbito de la posesión diabólica. En este sentido, Gil González toma a Blasco Lanuza como «un ejemplo de hombre arcaico, incapaz de diferenciar la naturaleza del espíritu». ${ }^{45}$

Existen dificultades metodológicas en la psicología retrospectiva, señaladas ya por Michel Foucault entre otros. ${ }^{46}$ In-

43 Blasco Lanuza 1652: 850

44 Gari Lacruz 1991: 172.

45 Gil González 2011: 193, cita en 114.

46 Foucault 2008: 22. Véase la crítica a la psicología retrospectiva de Clark 1997: 152 y 399. sistamos en que esta interpretación deja completamente de lado un elemento esencial de la cultura europea de la primera modernidad, en especial en el ámbito de la demonología: el discernimiento de fenómenos extraordinarios. ¿Qué nos dice sobre esto la obra de Blasco Lanuza? Veamos otra vez la frase del Patrocinio citada por Gari Lacruz, pero bajo las premisas del conflicto epistemológico temprano-moderno respecto del discernimiento, la demonología y la relación entre lo natural y lo preternatural. Asegura Blasco Lanuza que las campesinas de Tramacastilla y Sandiniés comenzaron a manifestar síntomas de «un genero de enfermedad tan secreta y extraordinaria que no podia darle alcance la diligente atencion de los médicos». ${ }^{47}$ Escribe esto para probar que una vez evidenciado el fracaso de la medicina secular, lo único que puede explicar esos males es la posesión diabólica. Los remedios naturales son ineficaces, sí, pero no porque la ciencia de la época fuera limitada - como exponen Gari Lacruz y Gil González-, sino porque, para Blasco, jamás podrían ser exitosos: tratan afecciones cuyas causas pertenecen a un orden de causalidad distinto al de la natura. Es crucial observar el momento en el cual se dan estas referencias a la medicina: en el Patrocinio, la infructuosa labor de los galenos suele aparecer simplemente para enaltecer, por contraste, los remedios espirituales. En una ocasión, Blasco Lanuza comenta de una posesa: «Dos años y medio padecia grandes accidentes, y atribuyan su enfermedad a mal de coraçon, y de la madre; aplicauanla remedios, y no era de prouecho [...]. Tratamos de exorciçarla, y de que frequentara los Sacramentos; y a pocos lances se mostraron los demonios, hablando por su boca». ${ }^{48} \mathrm{Y}$ en otro momento: «Visitòla vn Medico, y no siendo de prouecho la dexo, dando lugar a que obrassen los exorcismos; con ellos saliò la enfermedad, que era vn hechizo, à 2. de Febrero, dia de la Purificacion de la Madre de Dios» ${ }^{49}$ Como vemos, en una cruda operación de polarización, el remedio espiritual es exaltado en detrimento de la medicina natural. Agreguemos que el exorcismo funciona en el Patrocinio como un instrumento de discernimiento práctico a través del cual descartar de plano el origen natural de la afección. ${ }^{50}$

\section{EN DEFENSA DE LAS POSESAS: IMPOSTURAS}

¿Por qué esta sed por la exclusividad demoníaca en el diagnóstico? El último punto de la defensa que Blasco hace de las víctimas puede arrojar alguna luz sobre esto. No casualmente, es aquí donde la divergencia del autor con buena parte de la intelectualidad española del momento es más fuerte. En sus imprecaciones contra los que descreían de la epidemia en Tena, llega a comparar a católicos con «herejes» escépticos de la realidad de la posesión y el exorcismo: "Muchos herejes negaron eso y defendían que no entran los demonios en los cuerpos humanos». ${ }^{51}$ Es más:

47 Blasco Lanuza 1652: 835

48 Ibídem: 858.

49 Ibídem: 848.

50 Así interpreta el exorcismo Sluhovsky 2007: 75, 171, 207 y 229.

51 Blasco Lanuza 1652: 810. Y agrega: «No se contenta el demonio con perseguir al hombre, desde afuera [...]; en el mismo cuerpo se le encastilla (supuesta la permisio Diuina) y alli da muestras de la indignacion, que contra el tiene. Tan cierto es esto, que quien lo negasse seria hereje, porque esta expresso en la diuina Escritura». 
Decían que eran achaques, nacidos de flaqueza o delirios, o malicia fingida. Pero, que mucho diga esso, los que claramente son ministros del diablo, y estan ya alistados en sus compañias; isi entre Christianos, y muy doctos destos tiempos, auemos visto afirmar lo mismo, en las muchas obsessas, y algunos energumenos, que se han descubierto aora en el Valle de Tena, en Villanua, y en la Villa de Luna! ${ }^{52}$

Blasco Lanuza asocia aquí a católicos descreídos con herejes, mientras vuelve a negar cualquier explicación natural para la epidemia diabólica, rechazando la posibilidad de que las espiritadas estén enfermas, deliren, o peor, incurran en un fingimiento. Detengámonos en este último punto: la ansiedad de Blasco respecto del fingimiento se inserta en un problema que excede el ámbito hispánico, que posee escala europea. La falsedad y la impostura fueron a menudo objeto de perturbación en la cultura de la Europa temprano-moderna, obsesionada por su crisis de certeza..$^{53}$ Esto tuvo impacto en el ámbito del discernimiento y de la demonología, especialmente en el siglo XVII, cuando el esquema de discernimiento de fenómenos extraordinarios se complejiza al aportar a las opciones tradicionales de lo divino, lo demoníaco y lo natural, la posibilidad de la simple simulación. ${ }^{54}$ En efecto, esta sospecha solía pender sobre los endemoniados y de este recelo beberán en el siglo XVI tanto Michel Marescot en Francia como Reginald Scot y Samuel Harsnett en Inglaterra, por mencionar nuevamente a estos reconocidos opositores de la demonología radical europea en general y de la posesión diabólica en particular. El seiscientos profundizaría este camino. Hay multitud de ejemplos sobre esta ansiedad por la posesión fingida: podemos verla en Inglaterra con A guide to grandiury men (1627) de Richard Bernard y en Francia con las opiniones del médico escocés Marc Duncan sobre el célebre caso de la posesión de Loudun (1632-1637)..$^{55}$ Por supuesto, también en la España tempranomoderna puede apreciarse esta preocupación por la posesión simulada, que se inserta en la incertidumbre general por el correcto discernimiento de la realidad espiritual respecto de sus contactos con lo terreno, advirtiendo la posibilidad de la impostura humana. Veamos algunos ejemplos, para mejor tabular las impresiones de Blasco Lanuza.

Ya en el XVI temprano, el predicador Martín de Castañega anota el problema de la posesión fingida en su Tratado de las supersticiones y hechizerías de 1529, donde insiste en la necesidad de discernir con prudencia el verdadero origen de la posesión diabólica. El franciscano participa de una constante en la temática, fiel a la teología y la filosofía

\footnotetext{
52 Ibídem: 810-811.

53 Consúltese Berti 1999: 21-36; Eliav-Feldon 2012; Eliav-Feldon y Herzig 2015.

54 Campagne 2002: 303; Sluhovsky 2007: 187 y ss. Un proceso paralelo (ciertamente conectado con el problema de la posesión) es la preocupación teológica e inquisitorial por la santidad fingida. Al respecto, consúltese Keitt 2005; Zarri 1991.

55 Bernard aconsejaba a los jueces de las aldeas inglesas cuidarse de los posesos y sus engaños. Muchas veces, éstos apelaban a «meere counterfeiting of actions, motions, passions, distortions, perturbations, agitations, writhings, tumblings, tossings, wallowings, foamings, alteration of speech and voice, with gaftly soaring with the eyes: trances and relations of visions afterwards» (1627: 45). Por su parte, el médico escocés Duncan opinaba esto de las controvertidas posesiones de Loudun: "Ce ne seroit pas donc chose fort estrange si les Ursulines de Lodun contrefaisoyent les possedées» (1634: 11).
}

natural de la temprana modernidad: la precaución nunca es suficiente si se habla de mujeres. ${ }^{56}$ El disparador de la impostura suele ser bastante pedestre; hay innumerables casos en los que estas mujeres «fingen que están espiritadas o endemoniadas por algunos descontentos que tienen de sus esposos o maridos, o por grandes amores carnales». Si se reconoce fingimiento, sigue Castañega, no se debe prestar atención a la posesa ni a sus gestos: «No se curen dellas para darles audiencia, autoridad, ni crédito». ${ }^{57} \mathrm{~A}$ fines de siglo, la advertencia de Castañega seguiría vigente y Pedro Sánchez, autor de un Triangulo de las Tres virtudes Theologales, pedirá remedios más duros para casos similares. Comenta que en Toledo lo llamaron para que exorcizara "a una moça, que dezian estar endemoniada». Sospechoso del evento, propuso una cura infalible: «metida en la sacristia en presencia de su padre y deudos, la hize dar dos dozenas de açotes». ${ }^{58}$ La mujer acabó confesando la ficción: temía el castigo de su padre por haberse enredado con un hombre a sus espaldas. ${ }^{59}$

Durante el siglo XVII, la inquietud por la simulación diabólica se profundiza, insistiéndose no solo en la malicia de los engañadores, sino en la falta de idoneidad de los ministros de la Iglesia encargados de discernirlos. Gaspar Navarro y su Tribvnal de Superstición Ladina (1631) presenta una impostura intolerable: una falsa posesa que hablaba con voces diferentes, alternando suaves susurros -era Jesús quien sorprendía con cosas pías- y sonidos guturales - como si el demonio le contestara, blasfemando. Navarro reprende duramente a los eclesiásticos que se fiaron de la mujer, acompañándola en procesión y con antorchas a la iglesia, observando respetuosos cómo la supuesta endemoniada y mística consagraba la hostia y la depositaba en el sagrario. Condenaba sin más a todos los actores de semejante escena idolátrica: "No hay que espantarse de gente, a quien Dios dexa de su mano, y sigue embustes de mugeres ayudadas del Demonio".$^{60}$ Poco después, el jesuita Juan Chacon enviaría a su superior una relación sobre una endemoniada fingida, fechada en Valladolid, enero de 1635. Relata allí que una mujer «mas dama y cortesana que grosera, bien ensayada y con estilo diabólico, fingió tener espíritus»; copiaba a otra endemoniada que había sido conjurada unos pocos días antes. En esta condición logró hacerse de limosnas. Chacon resalta la impericia de los clérigos: la mujer logró convencer al exorcista del lugar, "un sacerdote bien experimentado en los exorcismos, aunque sujeto al engaño». En una ocasión ridícula, el mismo demonio tuvo que enseñarle al exorcista cómo conjurar correctamente: «Mira - decía el espíritu al sacerdote-, todo lo has hecho bien, salvo que la habias de mandar derribar primero, y

56 Recordemos que la demonología medieval y temprano-moderna, gracias a la teología y a la filosofía natural que la sustentan, es un discurso género-relacionado - esto es evidente respecto de la brujería. Véase la síntesis de Levack 2001.

57 Castañega 1997: 191-192.

58 Sánchez 1595: 174.

59 Es interesante notar que el comentario de Sánchez se incluye en una larga lista de autores del período que hicieron del ocultamiento de encuentros sexuales la razón primera para la simulación de la posesión diabólica. Nombremos, por ejemplo, el Entremés famoso de la endemoniada fingida de Francisco de Quevedo, para el cual véase Lisón Tolosana 1990: 99 y Morgado García 1999: 46.

60 Navarro 1631: 33. 
luego nos habias de conjurar, que como eres nuevo no lo entiendes». ${ }^{61}$ Aunque la condena, Chacon informa que la mujer fue socorrida y ocultada luego de confesado el embuste. Deja traslucir lo grave de la falta de impostura entre los encargados de imponer justicia en España: «Si la coge la justicia seglar, llevará azotes, y si la Inquisición, con ellos coroza. Si la cosa no es digna de leerse en público, V.R. la reserve para sí, y no se diga dónde sucedió, porque no pañare perjuicio á esta desventurada». ${ }^{62}$

El tópico de la posesión fingida también suele ser frecuente en las epidemias colectivas de endemoniados. La posesión conventual en San Plácido, por ejemplo, caso que con vaivenes ocupó a la Inquisición, a la Corona y al papado de 1626 a 1660, contó con lecturas que se inclinaron por denunciar al grupo de monjas como impostoras. Una de las religiosas interrogadas confió a los inquisidores que «nunca vio cosa alguna en las endemoniadas que esçediese las fuerças naturales»; otra, que los síntomas no eran nada "que no pudiese hacer qualquier persona o por enfermedad o algun accidente o invençion». El abad del monasterio vecino lo ponía sucintamente luego de visitar San Plácido: «era todo burleria»; el capellán iba todavía más lejos: «era embuste y mentira». Sobre los latines que se escuchaban de las bocas espiritadas - signo principal de la posesión, advertido, por ejemplo, en el Rituale romano- una testigo aseguró que las supuestas endemoniadas «lo pueden haber oído en sermones o leydo en libros vulgares». ${ }^{63}$

La cautela frente a las imposturas e impostoras diabólicas tomaría estatura legal, penetrando en diversas constituciones sinodales españolas. Aquellas dadas en el Obispado de Lugo en 1632, por ejemplo, enfatizan que es extraño encontrar endemoniados verdaderos en los tiempos presentes; la mayoría son mero fraude: «Aunque es Fe Catolica que huuo y puede auer endemoniados, mas ser tantos no es cosa creible». ¿Qué es lo que impulsa la aparición de tantos presuntos posesos? "Suele ser imaginacion de algunas mugerzillas, que por andar vagueando de un oraculo a otro, de romeria en romeria, fingen semejantes males». Las Constituciones dictaminan excomunión y encarcelamiento a estas engañadoras y ordenan al clero del lugar, por un lado, «dar cuenta primero a Nos, o a nuestro Prouisor, para que examinemos el negocio» y, por el otro, no prestar crédito alguno "a los que dizen estan espiritados, sin auer consultado con Medicos o personas doctas». ${ }^{64}$ Este tono, que deposita el control de los casos de posesión en la máxima autoridad eclesiástica y

61 Todas las citas, respectivamente, en Chacon 1861: tomo XIII, $125-126$ y $128-129$.

62 Ibídem: 125.

63 Todas las citas en Puyol Buil 1993: 169-171. Para la interpretación del fingimiento en el caso de San Plácido, véase Keitt 2005: 46. La sospecha de impostura en los casos colectivos de posesión era una tendencia general del seiscientos en toda Europa. Anotaciones laterales de un diplomático de Westfalia en la corte de Alejandro VII nos permiten acceder a las opiniones del papado respecto de los endemoniados de Padenborn, en el Sacro Imperio, episodio desatado entre 1656 y 1659 , que había llegado a interesar a Roma. Ninguno de los síntomas advertidos por el Rituale de 1614 para autenticar una posesión, comenta e papa, fueron presenciados; tan solo movimientos bruscos, espasmos, gesticulaciones, indicios fácilmente imitables. Se presentía así un engaño deliberado (Decker 2003: 169-170).

64 Constituciones Sinodales del Obispado de Lugo 1632: 117-118. privilegia sospechas de corte naturalista, se repetiría todo el siglo y el siguiente. En Málaga, en 1674, las actas ordenan prudencia a los exorcistas: «Si fuere la persona maleficiada muger, vayase con mucho espacio y consideracion, y no se resuelva con facilidad a hazer juyzio, porque estas acciones estan muy llenas de engaño». De hecho se le recomendaba al exorcista, frente a la impostura, disimular él mismo: «Nunca manifieste ni con palabra ni con señal, que lo cree, sino dissimule con prudencia, y lo disponga de modo que parezca que se inclina mas a la parte contraria, y todos los exorcismos, y diligencias que aplicare, sean con tal dissimulacion, que mas parezca que procede examinando y tentando, que no determinando y juzgando». ${ }^{65}$ El Sínodo de Zaragoza, más de veinte años después, repite a la letra estas recomendaciones y sentencia: «estas acciones estan muy llenas de engaño». ${ }^{66}$ Nuestra lista de ejemplos bien puede concluir con la mención del discurso Demoniacos del ilustrado Jerónimo de Feijóo, no tanto novedosa diatriba iluminista, sino decantación de un desarrollo intelectual crítico propio de la plena temprana modernidad. ${ }^{67}$

Creemos que es contra esta tendencia general del siglo que escribe Blasco Lanuza. Al tanto de la fuerte corriente de sospecha de la época respecto de la malicia o la debilidad física y mental constitutiva de las mujeres, el Patrocinio insiste en la realidad demoníaca de los síntomas desplegados por las posesas, sean afecciones corporales o visiones («aunque algunas vezes sucede en cabeças flacas de mugeres muchos delirios, y antojos, es cierto passan por ellas verdaderas visiones de Angeles y demonios»). ${ }^{68}$ Supeditar el evento diabólico del Valle de Tena a una ficción simulada le parece un triunfo del demonio. El Enemigo había llegado a cooptar en sus filas a las instancias judiciales que acusaban sin razón a las posesas. "He visto a muchos engañados deste modo - afirma-; y que han culpado grauissimamente a gente inculpada, infamandola de embriaga y lunatica, merecedora de palos, y castigos por Tribunales. Y esso es lo que pretendia el diablo». ${ }^{69}$ Blasco deja entrever una clara percepción respecto del distanciamiento de la intelectualidad española respecto de la demonología radical y de la dirección que ésta tomaba en el tratamiento de los posesos, crecientemente escrutados por los tribunales seculares, las autoridades eclesiásticas y la Inquisición como meros impostores o enfermos. ${ }^{70}$ Creemos que se equivocan, entonces, autores

65 Constituciones Synodales del Obispado de Malaga 1674: 353-354

66 Constituciones Sinodales de El Arçobispado de Zaragoza 1698: 175.

Feijóo 1739: tomo octavo. Sobre esto, véase Tausiet 2006b: 3-18.

8 Blasco Lanuza 1652: 850.

69 Ibídem: 815.

70 Desarrollo expuesto en Keitt 2005 y Sluhovsky 2007. Como insinuábamos más arriba (nota 54), el mismo proceso se verifica respecto de las revelaciones, los éxtasis, las meditaciones y contemplaciones, es decir, respecto del misticismo, en el marco de una desconfianza de la jerarquía eclesiástica, de su aparato represivo y de buena parte de la elite cultural frente a las manifestaciones terrenales incontroladas del mundo espiritual. El ejemplo más claro de esto último es, como se sabe, la condena papal de 1687 al aragonés Miguel de Molinos (1628-1696) y su Guía espiritual (1675), acusado de enseñar el anonadamiento y la aniquilación de la voluntad del alma mientras se deja libre al demonio los sentidos y miembros inferiores - lo que, aclaran las autoridades, llevaría a una indiferencia respecto de las ceremonias exteriores y, peor, a la creencia de que el pecado no podría ser imputado a la voluntad del 
como Gil González: en la época de la Contrarreforma, muchos intelectuales españoles, incluso cada vez más, afirman que los casos de posesión son en verdad producto de flaquezas, delirios o incluso imposturas. ${ }^{71}$ La fuerte defensa que Blasco realiza de las posesas, endemoniadas por voluntad de un brujo mediante un pacto con el Enemigo y sanadas por espectaculares exorcismos, es, no la norma, sino una excepción en la España de mediados del siglo XVII, donde el paradigma de la demonología radical (del cual la posesión diabólica es parte constitutiva) ya estaba hacía décadas puesto en entredicho - así lo atestiguan, por lo demás, las consecuencias teóricas y prácticas del célebre caso de brujería en Zugarramurdi-.$^{72}$

\section{EN DEFENSA DEL CRISTIANISMO: LA AMENAZA DE LA INCREDULIDAD}

Subrayemos, entonces, que el objetivo del relato de Francisco Blasco Lanuza no es combatir las prácticas populares, la ignorancia e impiedad del vulgo y el fingimiento en los contactos espirituales, todos ellos elementos señalados, satirizados, lamentados y castigados por la mayoría de la elite letrada católica, la justicia secular y la Inquisición durante buena parte del siglo XVII español. La interpretación del suceso de Tena en el Patrocinio está dirigida, por el contrario, a impugnar a aquellos que suplantan un ataque preternatural-demoníaco con humores melancólicos, astros, delirios e imposturas, intelectuales y agentes de los poderes seculares y eclesiásticos que yerran al momento de discernir correctamente la afección de las posesas. En efecto, en su diatriba llega, como vimos más arriba, a compararlos con los herejes quienes, dice, niegan tanto la posibilidad de la posesión como del exorcismo. Pero hay algo más:

A los que sin reparar en las señales, que tiene de serlo, se atreuen à dezir, que es inuencion de quimera, que estan embriagos, que es malicia dissimulada, que no puede ser demonios, los autores, y executores de semejantes enfermedades, se puede tener por sospechosos en la Fe; y de que no creen aya espiritus. ${ }^{73}$

hombre. Al respecto véase, entre otros, Pacho 1979: 1486-1514 y 1996: 85-108; Tellechea Idígoras 1987; Sluhovsky 2007: 116-129. En el mismo sentido, hacia fines del siglo XVII y más explícitamente en el siglo XVIII, el misticismo se considerará, junto con la demonología radical (lo veremos al final de este artículo), como ejemplos de superstición. Véase para esto Campagne 2016: 319-350; Heyd 1995.

71 Véase esta afirmación de Gil González: «La Contrarreforma no permite pensar a nadie por su cuenta, obliga a sostener a machamartillo un conjunto de creencias medievales que en vez de recortarse se desarrollan todavía más [...]. Nadie se atreve a decir públicamente que los achaques y aspavientos de los supuestos poseídos podrían ser todos ellos 'producto de su flaqueza, o de sus delirios, a veces fingidos' porque estarían poniendo en duda testimonios de los posesos curados por Jesucristo, que se mencionan en los textos de los Evangelios» (2011: 203). Véase también Morgado García: «Por aquél entonces nadie dudaba de la realidad de las posesiones demoníacas» (1999: 122).

72 Me refiero a la cristalización de una actitud escéptica frente el fenómeno brujeril, actitud expresada por el inquisidor Alonso de Salazar y Frías y por el humanista Pedro de Valencia, quien redacta para la ocasión su Discurso acerca de los cuentos de las brujas (1611). Recordemos que estas posiciones obtuvieron el favor de la Suprema en las instrucciones de 1614 acerca de cómo tratar en adelante los casos de brujería. La obra clásica sobre este tema sigue siendo Henningsen 1980 (hay edición española: Henningsen, G. 1983. El abogado de las brujas. Brujería vasca e Inquisición española. Madrid: Alianza Editorial).

73 Blasco Lanuza 1652: 811.
Quien atribuye la posesión a enfermedad o impostura es sospechoso de descreer de la existencia de los espíritus y por lo tanto es sospechoso respecto de su fe cristiana. Esta sentencia va al núcleo del problema que estamos intentando dilucidar aquí: el énfasis de Blasco Lanuza en la raíz plenamente demoníaca de las dolencias de las campesinas del Valle de Tena está relacionado de plano con la defensa de las bases metafísicas del cristianismo. La insistencia en la inocencia de las víctimas y en la realidad de las posesiones culminará con una admonición sugestiva acerca del significado último de esta epidemia, admonición que es a la vez una invectiva para aquellos que no supieron discernir el verdadero estatuto de las endemoniadas del valle de Tena. "Muchas vezes -advierte- entrega Dios al demonio sus escogidos». ${ }^{74}$

Es a partir de tomar a estas posesas como "escogidas» de Dios que Blasco seguirá la vía de la perceptibilidad de lo espiritual con el fin de sostener la realidad de lo sobrenatural en contra de aquellos que niegan las verdades metafísicas del cristianismo («no creen que aya espiritus»). En este sentido, el Patrocinio enrolará a las potencias infernales más como aliados que como enemigos. Blasco nos ofrece una pista suplementaria en esta dirección cuando se dispone a aclarar por qué decidió testimoniar el episodio de las posesas de Tena: "Aunque se halla escritos muchos sucessos de personas espiritadas, y en todos siglos se ha experimentado estas infestaciones de Satanas, que pudieron admirar a los racionales, dudo que aya precedido otro de mayor assombro en el mundo». ${ }^{75}$ Con esta apostilla breve («que pudieron admirar a los racionales»), la obra conecta el drama de la posesión demoníaca con el escepticismo respecto de los hechos fuera del orden de la natura. Sin embargo, no es desde la filosofía natural sino desde la historia, y en especial desde la historia sagrada, que Blasco argumentará, con los endemoniados, en contra de la descreencia. Efectivamente, el Patrocinio entrelaza los acontecimientos del Valle de Tena con el origen mismo del cristianismo, el paso del Mesías por la Judea antigua. Se emprende así una exégesis de la repetición, de la amplificación, de la inclinación a colocar los acontecimientos menores del momento en la estela del tiempo largo de la Salvación -en pocas palabras, la estrategia permanente del "acontecimiento sin fin» insinuada por Alain Boureau. ${ }^{76}$ La exégesis del presente en un racimo de aldeas olvidadas en la montaña aragonesa incita a Blasco a preguntar por qué Jesús encontró y liberó durante su ministerio a tantos posesos. «En la primitiva Iglesia - afirma - se descubrían muchos endemoniados porque reinaba ese yerro, de que no hay sustancias espirituales, ni eternidad $॥ .{ }^{77}$ Aquí, entonces,

\footnotetext{
74 Ibídem: 861.

75 Ibídem: 834. Blasco Lanuza realiza así una relectura muy interesante del tema clásico del combate entre el justo y el demonio, ubicando a las potencias infernales en el interior mismo de aquellos que más cerca están de la Divinidad: «En la tierra o poblado donde se alteran los demonios, manifestandose en los cuerpos de energumenos, y obsessos, es buena señal, y merece alabança: porque se haze guerra al demonio, y supone virtudes opuestas a su condicion» (ibídem: 832). Para una excelente síntesis del topos del combate entre el demonio y los justos, véase Sánchez Lora 2004: 161-186. Sobre la relectura de Blasco Lanuza respecto de la relación entre posesión y virtud, véase Campagne 2000 : 62-63.

76 Boureau 1993: 10.

77 Blasco Lanuza 1652: 818. Sobre la conexión que los demonólogos temprano-modernos solían hacer entre las posesiones contemporáneas
} 
la posesión diabólica sirve para evidenciar la verdad de la fe, la estructura de la creencia cristiana atravesada por el alma inmortal y su Juicio providente. De Asia a la península y del primer siglo al seiscientos, la epidemia diabólica del Alto Aragón actualiza las condiciones y los alcances de la Judea de la Primera Venida. Los posesos son queridos por Dios, tanto en tiempos hispánicos como en tiempos crísticos, para que:

Crean los Ateystas, hereges (que niegan sustancias espirituales, eternidad de almas, y vida eterna despues desta), que andan deslumbrados y den credito a los fundamentos infalibles de la Fe Catholica, viendo que hay innumerables demonios invisibles, por los efectos, que cabían visibles, que no pueden atribuirle a otra criatura. $^{78}$

Esta afirmación pone en evidencia la razón principal para relatar la epidemia de posesión de Tena: la defensa de la metafísica cristiana toda, con sus entidades espirituales, la inmortalidad del hombre y las geografías futuras - «los herejes Atheistas», remarcaba Blasco Lanuza con una fórmula ya estereotipada en su época, son aquellos que «niegan a Dios, y eternidad de almas, haciendo a las bestias iguales a los hombres». ${ }^{79}$ Blasco juzgó que los argumentos en contra del ateísmo bien podían apoyarse en la experiencia física de lo espiritual, esto es, en la materialización de lo invisible. En una palabra, a través de la potencia del discurso demonológico, el Patrocinio dio visibilización a la realidad invisible: el cuerpo poseído exhibe a los espectadores del drama de Tena tanto la existencia de almas y demonios presentes como la posibilidad de vislumbrar las geografías futuras, todo ello dispuesto por la Providencia. ${ }^{80}$

Blasco Lanuza apoya esta lectura de la posesión en los Comentarios del obispo de la Gante imperial, Cornelio Jansenio. ${ }^{81}$ Las referencias no son claras, pero quizá el pasaje que el Patrocinio tiene en mente es aquél en el que Jansenio, aludiendo a los endemoniados del Evangelio, afirma que la posesión diabólica habilita a entender que los hombres poseen un alma inmortal, aún cuando ésta no sea sensible: «ut etiam ostendatur esse substantias quasdam insensibiles,

y la Primera Venida de Cristo, véase Clark 1997: 412.

78 Blasco Lanuza 1652: 818

79 Ibídem: 747.

80 La vía demonológica a la creencia en verdades espirituales cristianas no siempre se utilizó, por supuesto, en contra del ateísmo. Tuvo usos a nivel pastoral. Léase al predicador lusitano de comienzos del siglo $\mathrm{XVII}$, Antonio Feo, quien incluye en sus sermones a los endemoniados porque "los males que el demonio haze en el cuerpo son visibles y palpables, y los que haze en el alma, invisibles». La absoluta perceptibilidad de la intrusión diabólica en los casos de posesión permite a Feo probar la realidad del alma humana, tan descuidada por la feligresía: «Veys los acidentes que un endemoniado padece, el no ver, no oyr, no hablar, echar espumajos por la boca, boluer los ojos en blanco, los visajes del rostro, el culebrear del cuerpo, el bracear y palpitar fuertemente: y no veys [...] los accidentes que causa en el alma; jazer postrada, hecha pedaços y palpitando: que si la viessedes, tendriades mucho dolor, y lastima della» (Feo 1614: 232). También Noydens utilizaría la posesión diabólica en este sentido en 1688: "Otros viendo, que vn cuerpo endemoniado en esta vida, es retrato de lo que passa en la otra, dan por razon, que Dios lo permite, por darnos vnos assomos de penas del Infierno, y dexarnos vnas sombras de los mismos demonios, que alla atormentan, para que ya que no los podemos ver la cara, saquemos temor de sus efectos, y nos sean ocasion muchas vezes de librarnos del Infierno» (1688: 100).

81 Jansenius 1684. Sobre Jansenio, véase Roegiers 1997: vol. 26, col. 942-947 ex quibus melius credere, ac intelligere possimus animas nostras esse immortales». La violencia sensible a la que los demonios, espíritus puros, someten al poseso («ex sensibili illa daemonum in eis quos secundum corpus obsident») llevará al fiel a comprender que hay una vida más allá de ésta, y que, para evitar el castigo, debe vivirla en el bien ( «ob quam in hac vita bene sit vivendum»). ${ }^{82}$ La interpretación que Blasco hace del ataque diabólico, apoyada quizá en estas líneas de Jansenio, es parte de una estrategia que requería evidenciar físicamente las verdades inasibles del dogma cristiano y que utilizó la figura del poseso en ese sentido.

Señalemos que las descreencias rechazadas por Francisco Blasco Lanuza no eran una novedad en España. Tanto Julio Caro Baroja como John Edwards, Javier Pérez Escohotado, Jesús Villanueva, Stuart Schwartz y María Lara Martínez, entre otros, señalan la presencia - sea en casos inquisitoriales concretos, en la apologética anti-libertina, en la dramaturgia, o quizá en la misma corte regia- de nutridas referencias materialistas, tales como la negación de las sustancias espirituales, de la inmortalidad del alma, de la Providencia y del paraíso e infierno. ${ }^{83} \mathrm{~A}$ comienzos del siglo XVII español, como en buena parte de Europa, se aprecia una tensión intelectual abierta en torno del problema de la incredulidad; en el extremo, esto se comprueba con la diseminación de los vocablos "ateísmo», "ateísta" y "ateo» en la literatura. ${ }^{84}$ Tenemos, por ejemplo, las páginas de las Diez lamentaciones de Jerónimo Gracián Dantisco, quien en su catálogo de ateos incluye "atheistas blasphemos» que niegan a Dios y "atheistas carnales y epicureos» que niegan la inmortalidad del alma, que ponen «los hados y el temor del infierno debaxo de sus pies» y que "no viven con mas cuydado que de nacer y morir» - ésta última, una fórmula que, con variantes, aparece impugnada en obras eruditas y en procesos y edictos inquisitoriales durante buena parte de Baja Edad Media y la temprana modernidad. ${ }^{85}$ El libro, redactado durante la estancia de Gracián en Flandes, está dirigido (así lo muestra su dedicatoria al Cardenal Bernardo de Rojas, inquisidor general) a alertar a los españoles respecto del crecimiento del ateísmo en aquellas zonas y el peligro que suponía su extensión - teme, incluso, una penetración del ateísmo en las Indias. El clima intelectual español a partir del segundo tercio del seiscientos, al decir de Jesús Villanueva, expondrá una conciencia mucho más palpable acerca de este problema, que por entonces se

82 Jansenius 1684: 184. Incluso un escéptico radical como el inglés Scot sabía que la cuestión de la existencia de los demonios era una temática sensible por su implicancia acerca de la existencia del alma: "There is no question nor theme [...] so difficult to deale in, nor so noble an argument to dispute upon, as this of divells and spirits. For that being confessed or doubted of, the eternitie of the soule is either affirmed or denied» (Scot 1584: 516).

83 Caro Baroja 1985: 213-222; Edwards 1988: 3-25; Lara Martínez 2013: 47-61; Pérez Escohotado 2003: 622-623; Schwartz 2008: 18, 22, 53, 61 y 75; Villanueva 2005.

84 Ibídem: 50. En la temprana modernidad, este término refiere no solo a quienes niegan a Dios, sino a quienes descreen de su providencia, de la inmortalidad del alma y de las geografías futuras (Arnold 2011: 225 y 229; Caro Baroja 1985: 216; Schwartz 2008: 75).

85 Gracián Dantisco 1611 (Lamentación primera y Lamentación tercera respectivamente). Sobre la fórmula «nascer y morir», a la que se suele atribuir una raíz judeoconversa pero cuyo uso no se agota en absoluto en este grupo, véase Caro Baroja 1985: 218; Cavallero 2014: 132-135; Edwards 1988: 19; Monsalvo Antón 1984: 109-139. 
asume, en escritos de autores como Bartolomé de Argensola, Saavedra Fajardo o Francisco de Quevedo, como un drama interno al reino en decadencia, en ocasiones infectando el mismo Alcázar del Rey Católico. ${ }^{86}$ La obra breve Providencia de Dios (c. 1641), que Quevedo dedica a condenar a «los Atheistas» que niegan "Dios, Providencia y Alma immortal» es una muestra de esta nueva ansiedad respecto de la incredulidad. ${ }^{87} \mathrm{El}$ caso extremo, suele señalarse, es aquél del médico andaluz Juan de Prado, cercano al deísmo y al libertinismo ya durante su formación en Alcalá de Henares entre 1627 y 1636, y luego exiliado en Amsterdam desde mitad de siglo, convertido a una variante particular de judaísmo naturalista; allí trabaría amistad con Baruch de Spinoza - y como él, sería excomulgado. ${ }^{88}$ Como podemos apreciar, la España del seiscientos conoce bien la amenaza de la descreencia y en este sentido las opiniones de Blasco no son más que una lectura en clave demonológica de un peligro que se asume como cada vez más urgente.

Al trazar la relación entre posesión e incredulidad, el Patrocinio repara en un dato no menor, la posición geográfica del Valle de Tena. Enfatiza que la región linda con el ducado francés de Béarn; es llamativo, dice, «el estar aqui tan vezinos de la Francia, por la parte que esta mas dañada de herejes, caluinistas, luteranos, ateystas». ${ }^{89}$ Blasco Lanuza alude así al peligro que España vive en sus días, cuando los enfrentamientos entre Luis XIII y Felipe IV en el marco de la Guerra de los Treinta Años y los conflictos al interior de la península empujan a los ejércitos franceses a penetrar en el norte del Imperio a comienzos de 1640. Y con esa invasión, teme Blasco, podría inocularse el veneno del ateísmo: «Ojala que ahora en estos Reinos de España, con la entrada de los Franceses en el de Cataluña, no se vaya extendiendo esta ponzoña»..$^{90}$ Esta amenaza territorial y espiritual, entonces, aporta el verdadero sentido de la epidemia de Tena: la Providencia ha enviado demonios al Valle para que la fe se imponga a los enemigos por medio de la visibilización, vía la posesión y el exorcismo, de las verdades metafísicas. Ateos y herejes «estan contemplando, en este apretado lance, la virtud de nuestra infalible ley»..$^{91}$ El Patrocinio explícitamente vincula los sucesos de Tena con la amenaza de la incredulidad:

Porque ahora cunde mucho, en la Francia, el error de los Ateystas, que niegan sustancias espirituales; y previene Dios, con tantos espiritados, esa infección de almas (dando al ojo con tantas evidencias de Ángeles malos) a los Españoles, para que no se deslumbren, siendo vecinos. ${ }^{92}$

\section{Villanueva 2005: 9}

87 La obra, publicada póstumamente, es Quevedo 1700: 6 . Notemos que en Defensa de Epicuro (1635), Quevedo estima que el filósofo, al contrario de lo que se le acusa, sí creyó en la inmortalidad del alma y, que si dijo que no había Dios, fue porque no gozaba de la fe que le hubiera permitido salir de su error.

88 Véase el reciente enfoque de Muchnik 2005.

89 Blasco Lanuza 1652: 837

90 Ibídem: 818. Era frecuente en el ámbito intelectual español remitir la presencia de la descreencia en suelo ibérico a un "contagio» venido del exterior (Schwartz 2008: 25; Villanueva 2005: 19). Algo similar solía ocurrir con el crimen de herejía (Villagrán 2003: 62) y con la brujería (Henningsen 1980: 128).

91 Blasco Lanuza 1652: 837

92 Ibídem: 792.
Tenemos aquí nuevamente el lenguaje de la experiencia, de la evidencia física de lo espiritual: la posesión es el antídoto con el que Dios previene a España del ateísmo importado de Francia, «disponiendo que den evidentes muestras los mismos demonios» de la verdad del cristianismo. ${ }^{93}$ Respecto de su juicio sobre el reino vecino, Blasco Lanuza estaba en lo correcto: aunque no podemos detenernos demasiado en esto, sí anotemos que la apologética católica de la Francia del seiscientos no se cansaría de vociferar en contra del peligro de la incredulidad. ${ }^{94}$ No eran solo advertencias: véase la suerte del filósofo italiano Giulio Vanini, quien en 1619 era acusado de ateo y trasladado a una horca y a una hoguera de Tolouse, con la lengua cercenada para evitar sus blasfemias - que no había ni Dios ni diablo, decían que gritaba a los espectadores. ${ }^{95}$ Aún muerto, su estela incrédula todavía era entrevista en el reino: el anónimo católico Effroyables pactions (1623) alertaba sobre la presencia en suelo francés de una secta, "les Inuisibles», seguidores de "la mesme methode que ce Philosophe Italien qui fut brulé à Thoulouze». Los sectarios, dice el anónimo, creen que el alma muere con el cuerpo, "ou que le corps fust sans ame»..$^{96}$ Ese mismo año, 1623, Jean Boucher, participante activo de los enfrentamientos entre hugonotes y católicos en la Francia de fines del siglo XVI, exclamaba que la expansión reciente de las sectas reformadas había generado la irreligión actual en la que Francia se hundía. Los ateos («Athées»), punto de llegada del quiebre confesional, eran negadores de la Providencia y de las bases del cristianismo, herederos de los «monstres de nature» de la Antigüedad (Diágoras, Teodoro, Luciano, Epicuro). No solo no creían "qu'il y a vn Dieu», sino que, como saduceos ("Sadducean»), negaban «l'immortalité de l'ame et de la vie eternelle». ${ }^{97}$ Todavía en 1623 François Garasse publicaba su masivo ataque a libertinos, deístas y ateos, La doctrine curieuse, donde celebraba la pira sacrificial de Vanini y clamaba por un destino similar para todos los descreyentes («Hélas! flammes de Sodome, ou estes vous!»). ${ }^{98}$ Un año después, el fraile mínimo Marin Mersenne se uniría a la defensa del cristianismo con su L'impieté des déistes, refutación del libelo incrédulo y anónimo Les Quatrians du déiste (1622), de profusa circulación. ${ }^{99}$ Por lo demás, apuntemos que no debería sorprendernos encontrar en la obra de Mersenne el recurso a los endemoniados como evidencia de las verdades metafísicas atacadas por Les Quatrians -en especial, el Juicio y el castigo infernal. Comenta Mersenne que los incrédulos son peores («pires») que los demonios; al menos estos últimos, nos dice la Escritura, saben que existe un Dios verdadero y le temen. ${ }^{100} \mathrm{Y}$

\footnotetext{
93 Ibídem: 818.

94 Sobre esta obsesión, véase Houdard 2008: 13. Para el problema de la incredulidad y sus diversas manifestaciones en la Francia del XVII, consúltese el clásico de Pintard 1943 y Kors 1990. Una síntesis de las líneas historiográficas actuales sobre la temática, en Cavaillé 2007.

95 Bahr 2007: «Prólogo», 9 y 15.

96 Effroyables Pactions faictes entre le diable et les pretendus inuisibles 1623: 6 y 27-28. Para este libelo, véase Houdard 2008: 40-41.

97 Boucher 1623: 46 y 424.

98 Garasse 1623. Así recuerda a Vanini: «Le temps viendra que Dieu fera brusler publiquement le miserable Lucilio» (851). Sobre las Ilamas de Sodoma, ibídem: 783.

99 Mersenne 1624. Para este epidosio apologético, consúltese el libro clásico de Betts 1984: 21-32; Popkin 2003: 78 y ss.

100 Mersenne 1624: 540. La referencia bíblica es Santiago 2, 19.
} 
nosotros, dice, podemos oír esa confesión de los demonios, "quand ils sont forcez de quitter les corps des possedez par la seule invocation du nom de lesus-Christ». ${ }^{101}$

Paradójicamente, entonces, en una Europa asediada por la crisis de certeza, por el conflicto religioso y por el crecimiento de la incredulidad, los demonios terminarán por constituirse en defensores de la fe cristiana. Los posesos y exorcistas del Patrocinio de Francisco Blasco Lanuza se insertan en una estrategia argumental que apela al hecho demonológico como evidencia ante los incrédulos renuentes a aceptar las realidades espirituales del cristianismo. ${ }^{102}$ Es por eso que, para el Patrocinio, lejos de ser impías, ignorantes, enfermas, delirantes o impostoras, las posesas son las «escogidas» de Dios. La Providencia divina, advierte Blasco, envía la epidemia diabólica para impedir que el ateísmo que corroe Francia se filtre en el reino ibérico. ${ }^{103}$ La condición necesaria para que las posesas pudieran ser signos sagrados estribaba -en tiempos de sospecha y discernimiento- en abolir cualquier otra interpretación que amenazara con arrancarlas de la mano providencial de la divinidad. $\mathrm{Ni}$ los astros, ni la melancolía, ni el fingimiento, ni la locura deben poder explicar esos sufrimientos. Es por eso que Blasco Lanuza utiliza decenas de páginas de su Patrocinio en asegurar, contra buena parte de una intelectualidad hispánica desde hacía décadas reticente a la demonología radical, y en esos momentos ya alejada de ella, que no existe en Tena impostura ni enfermedad. Solo entonces el trauma de la posesión demostraría a los incrédulos que las realidades espirituales existen. Porque a través de sus síntomas asombrosos, materializadas como expresión de invisibles demonios, las endemoniadas representan de un modo inequívoco las verdades metafísicas del cristianismo, atando la validez de lo espiritual al espectáculo visible de las sensaciones físicas. Estas «escogidas» se convierten para Blasco Lanuza en fuentes vivas de autoridad, cuerpos de evidencia que delinearán la terapéutica capaz de acabar con la plaga moderna de la incredulidad.

\section{CODA}

Las razones últimas del acento que Francisco Blasco Lanuza puso en la posesión diabólica en contra de la descreencia, la sospecha y las estrategias de naturalización ya bien asentadas en el siglo XVII fueron lateralmente advertidas, no casualmente, por una obra estrictamente contemporánea e incrédula al momento de tratar con el problema del alma, los demonios, la posesión y las geografías futuras: el Leviathan (1651) de Thomas Hobbes. Hobbes indica que la idea de posesión espiritual surgió entre los paganos, pasó al pueblo judío y de allí infestó al cristianismo temprano. La razón del éxito de esta construcción en el medio hebreo fue, sin dudas,

101 Mersenne 1624: vii.

102 Para la relación entre demonología e incredulidad, véase Stephens 2001. Anotemos que la estrategia utilizada por Blasco Lanuza sería desplegada a fines del siglo XVII por intelectuales como Glanvill 1681. Véase al respecto Cameron 2010: 241-246 y 270-285.

103 En este sentido, no creemos que el objetivo primero de Blasco Lanuza fuera, tal como plantea María Tausiet, blandir la posesión diabólica en contra de la amenaza de la herejía protestante y como medio para evangelizar a las poblaciones de esa zona montañosa (Tausiet 2009: 140). el insuficiente deseo por investigar causalidades naturales. Los judíos se aprestaron así a suponer vectores espirituales para los fenómenos extraordinarios:

For they that see any strange, and unusual ability, or defect in a mans mind; unless they see withall, from what cause it may probably proceed, can hardly think it naturall; and if not natural, they must needs think it supernatural; and then what can it be, but that either God, or the Devil is in him ${ }^{104}$

Este error llevó a tomar cualquier síntoma extravagante como una posesión espiritual, en lugar de simplemente tratar a las víctimas como lo que realmente eran: enfermos. Sin embargo, advierte el Leviathan, no todos los judíos coincidían aquí:

Whosoever behaved himself in extraordinary manner, was thought by the Jews to be possessed either with a good, or evil spirit; except by the Sadducees, who erred so farre on the other hand, as not to believe there were at all spirits (which is very near to direct Atheism) and thereby perhaps the more provoked others, to term such men Demoniacks, rather than mad-men. ${ }^{105}$

No todos los judíos, entonces, se dejaban convencer por las explicaciones sobrenaturales. En los tiempos del Antiguo Testamento, dice Hobbes, los Saduceos descreían de las posesiones espirituales justamente porque cuestionaban la existencia de toda entidad espiritual. ${ }^{106}$ Hobbes parece darnos la clave para comprender la estrategia demonológica del Patrocinio: así como los judíos convencidos del mundo invisible insistieron en la realidad de la posesión frente a los incrédulos, así en la Europa del seiscientos ciertos cristianos la defendieron en contra de los modernos saduceos. Blasco Lanuza, en alianza con los demonios, fue uno de ellos.

Sin embargo, esta alianza tendría un alto costo en la Europa del siglo XVII y más allá: solaparse con la superstición. Notemos al pasar que ya en 1611, en su crítica a la brujería, el humanista Pedro de Valencia había neutralizado el valor de apelar al demonio para preservar la verdad de la fe. Hay quienes afirman, comentaba, "que es señal de cristianos el creer que hay demonios, y de lo contrario el tener por burla todos sus cuentos y manifestaciones». Valencia disiente: no es eso lo que caracteriza al hombre de fe. Es más, la creencia en la realidad del demonio "solamente sería muestra, como lo es toda superstición, de no ser ateísta». ¿Es ello de alguna utilidad? De ninguna manera. Que «políticos, epicúreos o lucianistas» no confíen más que en las "cosas naturales y corpóreas que experimentan» no debe hacernos creer en "consejas de las viejas y [en] todas las fábulas gentilicias y hacer verosímiles todas las metamorfosis de Ovidio». En pocas palabras, la existencia de incrédulos no debe empujarnos al extremo contrario, la credulidad. ${ }^{107}$ Como vemos, la estrategia demonológica que Francisco Blasco Lanuza utilizaría a mediados del seiscientos ya era percibida por algunos como un pensamiento vano, más del lado del ridículo que de la sana apologética. Los cruces entre

104 Hobbes 1651: 38.

105 Ibídem: 38.

106 Son aquellos que niegan los espíritus, inmortalidad del alma, castigos o recompensas futuras y resurrección, como puede verse en Hechos 23, 8; Marcos 12, 18; Mateo 22, 23; Lucas, 20, 27.

107 Valencia 1997: tomo VII, 286-287. 
discernimiento, demonios e incredulidad en las décadas finales del siglo XVII europeo confirmarían esa tendencia hacia la progresiva convergencia de la demonología radical con el espectro de la superstición. ${ }^{108}$

\section{FUENTES}

Bernard, R. 1627. A Guide to Grand lury men. London: Blackmore.

Blasco Lanuza, F. 1652. Patrocinio de ángeles y combate de demonios. Real Monasterio de San Juan de la Peña.

Boucher, J. 1623. Couronne mystique. Tournay.

Castañega, M. 1997. [1529]. Tratado muy sotil y bien fundado de las supersticiones y hechicerías. Edición de F. Campagne. Buenos Aires: Facultad de Filosofía y Letras de la Universidad de Buenos Aires.

Constituciones Sinodales de El Arçobispado de Zaragoza. 1698. Zaragoza.

Constituciones Sinodales del Obispado de Lugo. 1632. Madrid: Iuan Gonçalez.

Constituciones Synodales del Obispado de Malaga. 1674. Sevilla: Viuda de Nicolás Rodríguez.

Chacon, J. 1861. "Relación de la endemoniada fingida», en Memorial Histórico Español. Colección de Documentos, Opúsculos y Antigüedades: tomo XIII. Madrid: Real Academia de Historia.

Duncan, M. 1634. Discours de la Possession des Religieuses Ursulines de Lodun. Saumur: Lesnier.

Effroyables Pactions faictes entre le diable et les pretendus inuisibles. 1623. Paris.

Feijóo, J. 1739. «Demoniacos», en Theatro Critico Universal, o Discursos varios en todo género de materias, para desengaño de errores comunes: tomo octavo. Madrid: Herederos de Francisco del Hierro.

Feo, A. 1614. Tratados Quadragesimales. Valencia. [Traducidos del portugués por Fray Thomas de Antillon de la Orden de San Agustín].

Garasse, F. 1623. La Doctrine Curieuse des Beaux Esprits de Ce Temps. Paris: Chappelet.

Glanvill, J. 1681. Saducismus Triumphatus. London: James Collins.

Gracián Dantisco, J. 1611. Diez lamentaciones del miserable estado de los atheistas de nuestros tiempos. Bruselas: Roger Velpio y Hubert Antonio.

Harsnett, S. 1599. A Discovery of the fraudulent practises of lohn Darell. London.

Hobbes, T. 1651. Leviathan. London: Andrew Crook.

Huarte de San Juan, J. 1575. Examen de ingenios para las sciencias. Baeza: Juan Bautista de Montoya.

Indice ultimo de los Libros Prohibidos y mandados expurgar. 1790 Madrid: Antonio de Sancha.

Jansenius, C. 1684. [1571]. Commentarium in suam Concordiam, ac totam Historiam Euangelicam partes IIII. Edición de C. de la Roche. Lyon.

Jorden, E. 1603. A briefe discourse of a disease called the Suffocation of the Mother. London: John Windet.

Kramer, H. 2006. [1486]. Malleus Maleficarum. Volume I: The Latin Text. Edición de C. Mackay. Cambridge: Cambridge University Press.

Luis de la Concepción 1673. Práctica de conjurar. Alcalá de Henares: Francisco García Fernández.

Marescot, M. 1599. Discours veritable sur le faict de Marthe Brossier de Romorantin, pretendue demoniaque. Paris: Mamert Patisson.

Mercado, P. 1558. Dialogos de Philosophia natural y moral. Granada: Hugo de Mena y Rene Rabut.

Mersenne, M. 1624. L'impiété des Déistes, Athees, et Libertins de ce temps. Paris: Pierre Bilaine.

108 Véase Cameron 2010: 268; Campagne 2002: 27 y 600-608. ¿Sorprende, a la luz de estos desarrollos históricos, que el ilustrado siglo XVIII español ordenara expurgar el Patrocinio de ángeles y combate de demonios? (Indice ultimo de los Libros Prohibidos y mandados expurgar 1790: 154. El edicto de expurgación es de junio de 1750).
Navarro, G. 1631. Tribvnal de Superstición Ladina. Huesca: Pedro Bluson.

Noydens, B. R. 1688. Practica de Exorcistas y Ministros de la Iglesia. Barcelona.

Padilla Manrique y Acuña Aranda, L. M. 1640. Elogios de la verdad e invectiva contra la mentira. Zaragoza.

Pellizer y Tobar, J. 1790. "Avisos historicos, que comprehenden las noticias y sucesos mas particulares, ocurridos en nuestra Monarquia desde el año de 1639», en A. Valladares de Sotomayor, Semanario Erudito: XXXII, Madrid: Antonio Espinosa.

Quevedo, F. 1700. Providencia de Dios, padecida de los que la niegan y gozada de los que la confiessan. Zaragoça: Pasqual Bueno.

Ritvale Romanvm Pavli V Pontifice Maximum IVssv Editvm. 1679. Venecia: Guerilios.

Sánchez, P. 1595. Triangulo de las Tres Virtudes Theologicas. Toledo.

Scot, R. 1584. The Discoverie of Witchcraft. London.

Tomás de Aquino. 1982. [c. 1270]. Quaestiones disputatae de Malo. Roma-Paris: Comissio Leonina-Vrin.

Torquemada, A. 1575. Jardín de Flores Curiosas. Amberes. [Ed. J. Corderio].

Valencia, P. 1997. [1611]. "Discurso acerca de los cuentos de las brujas», en Obras completas: tomo VII. León: Secretaría de Publicaciones de la Universidad de León.

Vanini, G. 1616. De admirandis. Lutetiae: Adrianum Perier.

Wier, J. 1567. [1563]. Cinq Livrs de I'Imposture et Tromperie des Diables. Edición de J. Grévin. Paris.

\section{BiBLIOGRAFÍA}

Arnold, J. 2011. Belief and Unbelief in Medieval Europe. London-New York: Bloomsbury.

Atienza, B. 2009. El Loco en el Espejo. Locura y Melancolía en la España de Lope de Vega. Ámsterdam: Rodopi.

Bahr, F. (ed.). 2007. Los Maravillosos Secretos de la Naturaleza, Reina y Diosa de los Mortales. Buenos Aires: El Cuenco de Plata.

Berti, S. 1999. «Unmasking the Truth: the theme of Imposture in Early Modern European Culture, 1660-1730», en J. Force y D. Katz (eds.), Everything Connects: In conference with Richard H. Popkin: 21-36. Leiden: Brill.

Betts, C. 1984. Early Deism in France. From the so-called "déistes» of Lyon (1564) to Voltaire's Lettres philosophiques (1734). The Hague: Martinus Nijhoff.

Biard, J. y Gontier, T. (dir.). 2009. Pietro Pomponazzi entre traditions et innovations. Amsterdam: Grüner.

Boureau, A. 1993. L'Événement sans fin. Récit et christianisme au Moyen Âge. París: Les Belles Lettres.

Caciola, N. 2003. Discerning Spirits: Divine and Demonic Possession in the Middle Ages. Ithaca: Cornell University Press.

Caciola, N. y Sluhovsky, M. 2012. "Spiritual Physiologies: The Discernment of Spirits in Medieval and Early Modern Europe». Preternature 1 (1): 1-48.

Cameron, E. 2010. Enchanted Europe: Superstition, Reason and Religion, 1250-1750. Oxford: Oxford University Press.

Campagne, F. 2000. «El otro-entre-nosotros. Funcionalidad de la noción de superstitio en el modelo hegemónico cristiano (España, siglos XVI y XVII)». Bulletin Hispanique 102 (1): 37-63.

Campagne, F. 2002. Homo catholicus, Homo Superstitiosus. El discurso antisupersticioso en la España de los siglos XV a XVIII. Buenos Aires: Miño y Dávila.

Campagne, F. 2011. "Demonology at a crossroads: the visions of Ermine de Reims and the image of the devil on the eve of the great European witch-hunt». Church History 80 (3): 467-497.

Campagne, F. 2016. Profetas en ninguna tierra. Una historia del discernimiento de espiritus en Occidente. Buenos Aires: Prometeo.

Caro Baroja, J. 1985. Las formas complejas de la vida religiosa (Siglos XVI y XVII). Madrid: Sarpe.

Cavaillé, J.-P. 2007. "Libertinage, irréligion, incroyance, athéisme dans l'Europe de la première modernité (XVle-XVIle siécles). Una approche critique des tendances actuelles de la recherche (1998-2002)». Les Dossiers du Grihl 2. [Texto electrónico: http:// dossiersgrihl.revues.org/279]. 
Cavallero, C. 2014. «Judíos, conversos y 'malos christianos' en e Fortalitium fidei de Alonso de Espina: la mirada del Cíclope ante una encrucijada decisiva (Castilla, siglo XV)», en F. Campagne (ed.), Poder y Religión en el mundo Moderno. La cultura como escenario del conflicto en la Europa de los siglos XV a XVIII: 117-162. Buenos Aires: Biblos.

Clark, S. 1997. Thinking with Demons. The idea of Witchcraft in Early Modern Europe. Oxford: Oxford University Press.

Contreras, J. 2002. «Procesos culturales hegemónicos: de Religión y Religiosidad. Reflexiones sobre el hecho religioso. La España de Antiguo Régimen", en Fundación V. Actas de las Primeras Jornadas de Historia de España. Tomo V: 9-38. Buenos Aires: Fundación para la Historia de España.

Copeland, C. y Machielsen, J. (eds.). 2013. Angels of Light? Sanctity and Discernment of Spirits in the Early Modern Period. Leiden: Brill.

Daston, J. 2000. "Preternatural Philosophy», en L. Daston (ed.), Biographies of Scientific Objects: 15-41. Chicago-London: The University of Chicago Press.

Daston, L. 1991. "Marvelous Facts and Miraculous Evidence in Early Modern Europe». Critical Inquiry 18 (1): 93-124.

Decker, R. 2003. Witchcraft and Papacy: an account drawing on the formerly secret records of the Roman Inquisition. Charlottesville London: University of Virginia Press.

Duché-Gavet, V. (ed.). 2003. Juan Huarte au XXIe siècle. Anglet: Atlantica.

Edwards, J. 1988. «Religious Faith and Doubt in Late Medieval Spain: Soria circa 1450-1500». Past and Present 120: 3-25.

Eliav-Feldon, M y Herzig, T. (eds.). 2015. Dissimulation and Deceit in Early Modern Europe. Basingstoke: Palgrave MacMillan.

Eliav-Feldon, M. 2012. Renaissance Impostors and Proofs of Identity. Basingstoke: Palgrave Macmillan.

Evans, G. 1994. Augustine on Evil. Cambridge: Cambridge University Press.

Foucault, M. 2008. "Médicos, jueces y brujos en el siglo XVII», en M. Foucault, La vida de los hombres infames: 13-22. La Plata: Altamira.

Gambin, F. 2008. Azabache. El debate sobre la melancolía en la España de los Siglos de Oro. Madrid: Biblioteca Nueva.

Gari Lacruz, A. 1991. Brujería e inquisición en el Alto Aragón en la primera mitad del siglo XVII. Zaragoza: Diputación General de Aragón \& Departamento de Cultura y Educación.

Gibson, M. 2006. Possession, Puritanism, and Print: Darrell, Harsnett, Shakespeare, and the Elizabethan Exorcism Controversy. London: Pickering \& Chatto.

Gil González, G. 2011. A la luz de los prodigios. Almas, demonios y seres evanescentes, mitos y mundos en el Siglo de Oro. Madrid: Miraguano.

Henningsen, G. 1980. The Witches' Advocate. Basque Witchcraft and the Spanish Inquisition. Reno: University of Nevada Press.

Heyd. 1995. "Be sober and reasonable»: The Critique of Enthusiasm in the Seventeenth and Early Eighteenth Centuries. Leiden: Brill.

Houdard, S. 2008. Les Invasions Mystiques: Spiritualités, Hétérodoxies et Censures au début de l'époque moderne. Paris: Les Belles Lettres.

Kallendorf, H. 2004. "Cervantes y la posesión demoníaca: El rufián dichoso, Blasco de Lanuza y el Ars moriendi», en A. Villar Lecumberri (ed.), Peregrinamente Pregrinos. Actas del V Congreso Internacional de la Asociación de Cervantistas: 1449-1466. Lisboa: Asociación de Cervantistas.

Kamen, H. 1998. Cambio Cultural en la Sociedad del Siglo de Oro. Cataluña y Castilla, siglos XVI-XVII. Madrid: Siglo XXI.

Keitt, A. 2005. Inventing the sacred. Imposture, Inquisition, and the Boundaries of the Supernatural in Golden Age Spain. Leiden: Brill.

Klibansky, R. et al. 1964. Saturn and Melancholy. Studies in the History of Natural Philosophy, Religion and Art. Nelson: London.

Kors, A. C. 1990. Atheism in France, 1650-1729: the Orthodox Sources of Disbelief. New Jersey: Princeton University Press.

Lara Martínez, M. 2013. Brujas, Magos e Incrédulos en la España del Siglo de Oro. Microhistoria cultural de ciudades encantadas. Cuenca: Aldebarán.

Levack, B. (ed.). 2001. Gender and Witchcraft. New York: Routledge.

Levi, G. 1990. La herencia inmaterial. La historia de un exorcista piamontés del siglo XVII. Madrid: Nerea.

Lisón Tolosana, C. 1990. La España mental. Demonios y Exorcismos en los Siglos de Oro. Madrid: Akal.
Mandressi, R. 2006. «Les médecins et le diable». Chrétiens et sociétés 13. [Texto electrónico: http://chretienssocietes.revues.org/2111].

Monsalvo Antón, J. M. 1984. «Herejía conversa y contestación religiosa a fines de la Edad Media. Las denuncias de la Inquisición». Studia Historica. Historia Medieval 2 (2): 109-139.

Morgado García, A. 1999. Demonios, magos y brujas en la España Moderna. Cádiz: Servicio de Publicaciones de la Universidad de Cádiz.

Morgado García, A. 2000. «Ángeles y demonios en la España del Barroco». Chronica Nova 27: 107-130.

Muchnik, N. 2005. Une vie marrane: Les pérégrinations de Juan de Prado dans l'Europe du XVIle siècle. Paris: Honoré Champion.

Ossa-Richardson, A. 2013. The Devil's Tabernacle: The Pagan Oracles in Early Modern Thought. Princeton: Princeton University Press.

Pacho, E. 1979. "Molinos», en M. Viller y J. Cavallera y De Guibert (eds.), Dictionnaire de Spiritualité Ascètique et mystique 10: 14861514. Paris: Beauchesne.

Pacho, E. 1996. «El misticismo de Miguel de Molinos. Raíces y proyección», en L. López Beralt y L. Piera Delgado (eds.), El sol de medianoche. La experiencia mística: tradición y actualidad: 85108. Madrid: Trotta

Pelletier, M. 1998. Marthe Brossier, Henri IV et les Ligueurs: exorcisme, procès et exil d'une possédée solognote. Paris: Royer.

Pérez Escohotado, J. 2003. Antonio de Medrano, alumbrado epicúreo: proceso inquisitorial (Toledo, 1530). Madrid: Verbum.

Pine, M. 1986. Pietro Pomponazzi: radical philosopher of Renaissance. Padua: Antenore.

Pintard, R. 1943. Le libertinage érudit dans la première moitié du XVII siècle. Paris: Boivin.

Popkin, R. 2003. History of scepticism from Savonarola to Bayle. Oxford: Oxford University Press.

Prosperi, A. 1996. Tribunali della coscienza. Inquisitori, confessori, missionari. Torino: Einaudi.

Puyol Buil, C. 1993. Inquisición y Política en el reinado de Felipe IV. Los Procesos de Jerónimo de Villanueva y las monjas de San Plácido 1628-1660. Madrid: CSIC.

Radden, J. (ed.). 2000. The Nature of Melancholy. From Aristotle to Kristeva. Oxford-New York: Oxford University Press.

Read, M. 1981. Juan Huarte de San Juan. Boston: Twayne.

Roegiers, J. 1997. "Jansénius (Corneille)», en Dictionnaire d'Histoire et de Géographie Ecclésiastiques: vol. 26, col. 942-947. Paris: Letouzey.

Sánchez Lora, J. L. 2004. "Demonios y santos: el combate singular», en M. Tausiet y J. Amelang (eds.), El Diablo en la Edad Moderna: 161186. Madrid: Marcial Pons.

Schreiner, S. 2011. Are You Alone Wise? The Search for Certainty in the Early Modern Era. Oxford: Oxford University Press.

Schwartz, S. 2008. All can be saved. Religious Tolerance and Salvation in the Iberian Atlantic World. New Haven: Yale University Press.

Sluhovsky, M. 2007. Believe Not Every Spirit. Possession, Mysticism \& Discernment in Early Modern Catholicism. Chicago: The University of Chicago Press.

Stephens, W. 2001. Demon Lovers: Witchcraft, Sex and the Crisis of Belief. Chicago: University of Chicago Press.

Tausiet, M. 2006a. "'Patronage of angels and combat of demons': good versus evil in seventeenth-century Spain", en P. Marshall y A. Walsham (eds.), Angels in the Early Modern World: 233-255. Cambridge: Cambridge University Press.

Tausiet, M. 2006b. «De la ilusión al desencanto: Feijoo y los 'falsos posesos' en la España del siglo XVIII». Historia Social 54: 3-18.

Tausiet, M. 2009. «La batalla del Bien y el Mal: 'Patrocinio de Ángeles y combate de Demonios'». Hispania Sacra LXI (123): 125-146.

Tellechea Idígoras, J. I. 1987. Molinosiana. Investigaciones históricas sobre Miguel de Molinos. Madrid: FUE.

Villagrán, G. 2003. La palabra del predicador: Contrarreforma y superstición en Cataluña (siglos XVII-XVIII). Tesis doctoral dirigida por el Dr. R. García Cárcel. Universidad autónoma de Barcelona: Departamento de Historia Moderna y Contemporánea.

Villanueva, J. 2005. «Remarques á propos de l'historiographie sur le libertinisme espagnol du XVIle siécle». Les Cahiers du Centre de Recherches Historiques 35. [Texto electrónico: http://ccrh.revues. org/3028].

Zarri, G. (ed.). 1991. Finzione e santità tra medioevo ed età moderna. Torino: Rosenberg \& Sellier. 